trials. The field performance of both insecticides had been improved by increasing the volume of water from 5 to 10 gal. per acre, and by applying the insecticide directly to the cocoa trees, particularly the trunk and pods, instead of the general dispersion used previously with lindane. A discussion of the several methods that had becn used to evaluate the effectiveness of insecticides for mirid control followed.

Two papers were then read on the possible side-effects of insecticides. Mr. Peterson described precautionary tests carried out to detect whether taint and residues are present in chocolate manufactured from cocoa treated with insecticides. Dr. B. M. Gerard described tests to detect undesirable effects of insecticides on insects other than mirids. It is known that dieldrin ${ }^{2}$, heptachlor and chlordane $e^{3}$ eause increases in numbers of some minor cocoa pests while lindane has not had any obvious sideeffects of this nature. The present tests consisted of monthly applications of 'Sevin', 'Sumithion', lindane and water; after five applications, minor pest populations had not increased noticeably on any of the treated plots, insect pollination seemed unaffected and ants (the most numerous predatory insects on cocoa trees) seemed to be only slightly affected. To minimize the chances of upsetting the ecological balance an insecticide with a narrow spectrum or very short persistence would be preferable.

The final paper on August 6 was a plea by Dr. Gerard for more collaboration between cocoa research stations in West Africa. Cocoa research in the nine West African countries growing this crop was becoming increasingly isolated. Collaboration could prevent unnecessary duplication of experiments, lead to simplification of some investigations and provide an impetus for many lines of research. If entomologists in West Africa could cooperate in a survey of the relationship between cocoa mirids and controlling agents it might be possible to eradicate these species from some areas. In Ghana, $S$. singularis was a major pest only ten years previously, but for at least the past two years had been difficult to find; $D$. theobroma had not decreased to the same extent. Differences between these species include parasitism. 7-31 per cent recorded for $S$. singularis ${ }^{4}$ and virtually nil for $D$. theobroma, and the greater activity of $S$. singularis which could render it more vulnerable to insecticides ${ }^{1}$ He suggested that lindane may have played an important part in this near-eradication, as in addition to being an efficient miridicide it had a short persistence so that any mirids surviving treatment could be attacked by parasites only a few days later. Suggestions were made for improving control of cocoa pests.

Representatives gave details of methods used for mirid control in Nigeria, Ivory Coast and Cameroun, and the importance and distribution of the two mirid species in these countries. It was agreed that collaboration was desirable, and a further conference at Ibadan, Nigeria, has been arranged for March 1964 .

Informal discussions on collaboration continued on August 7. Apparatus and techniques used in insecticide tests and rearing in the laboratories were demonstrated. Mr. A. A. Laryea explained the method for detecting resistant mirids used by the Cocoa Disease and Pest Control Unit previously described by Mr. Telford. The Unit's spraying machine repair shop at Bunso was visited in the afternoon.

The Proceedings of this meeting are now available from the Librarian of the Cocoa Research Institute of Ghana, P.O. Box 8, Tafo, Akim, Ghana.

B. M. Gerard

${ }^{1}$ Dunn, J. A., Nature, 199, 1207 (1963).

2 Entwistle, P. F., Johnson, C. G., and Dunn, E., Nature, 184, 2040 (1959).

${ }^{3}$ Armstrong, K. B., Rep. W. Afr. Cocoa Res. Inst., 1961-62, 28 (1963).

${ }^{4}$ Anon., Rep. W. Afr. Cocoa Res. Inst., 1944-45, 26 (1946).

\title{
THE EXPERIMENTAL ANIMAL IN RESEARCH
}

$\mathrm{A}^{\mathrm{s}}$ $\mathrm{N}$ advanced study institute on the general topic of "The Experimental Animal in Research" was held in Harrogate during September 9-20, 1963.

The North Atlantic Treaty Organization, which has always shown the greatest interest in fostering international scientific co-operation, financially supported the meeting. It was organized by Dr. W. Lane-Petter, director of the Laboratory Animals Centre (Medical Research Council) and honorary secretary of the International Committee on Laboratory Animals, and his colleagues. There were altogether 90 participants from 17 countries. The idea of the organizers was to create something different from the usual symposia or congresses and provide an atmosphere free from pressure of time. Hence, ample time was allowed to each speaker to reveal his ideas, and the chairman was not compelled to interrupt the discussion of the paper on account of the clock. In addition, all the participants were accommodated in the same hotel and were thus given every opportunity to know each other and to have informal discussions out of working hours. Harrogate, a traditional place for meetings of all kinds, and its surroundings, offered recreations and facilities for excursions.

This advanced study institute was the third of a series of international meetings devoted entirely to laboratory animals. The first meeting of the kind was the symposium on "Living Animal Material for Biological Research"1, held in 1958 at Gif-sur-Yvette (France). The object of this international confrontation was to define the needs of biological research, examine the present situation and see what could be done to meet the demands of modern biology. In 1961, in Czechoslovakia, the second inter- national symposium on "The Problems of Laboratory Animal Disease"2 was held. Disease is the first problem in laboratory animals science. The different papers did not aim at being a complete review of individual diseases as such, but the purpose was mainly to consider, even when dealing with a specific disease, the phenomenon of transmissible diseases in laboratory animals from the point of view of ætiology, epidemiology, control and eradication.

The third subject, "The Experimental Animal in Research", was a very broad one indeed. But it was in fact with design that the institute was not restricted to a specific subject. This was felt to be the best approach to detect all present general trends concerning the needs of modern biological research and the different problems in the production of adequate laboratory animals. In the introductory session, some few examples stressed the importance of the laboratory animal in research and of its shortcomings, the necessity for well-defined laboratory animals and hence the need for a terminology carrying universal acceptance. Then, problems concerning management in general and the different aspects of production were presented by several speakers. Produetion of highquality animals is possible only if a sound organization is set up with adequate facilities and well-trained competent personnel. The production of good laboratory animals is not a problem of husbandry only. There is also the problem of controlling the characteristics for which the animals are produced. It entails complex scientific and technical problems and a galaxy of talents that, of course, cannot be realized in each production unit. Hence the necessity arises of having 'primary type colonies', where the maximum of control is brought to bear on all 
individuals. From these colonies production units can obtain breeding pairs for sub-cultivation to a limited number of generations. Control of quality is important.

Quality, as applied to a laboratory animal, is not a general characteristic easy to define, but is "the combination of a variety of factors dependent upon its parentage, its environment, its nutrition and the contact it has had with disease producing agents"3. Strains of laboratory animals which are maintained by strict inbreeding are not necessarily homozygous for all their genes. Even after a great number of generations of inbreeding, there are different sources of genetic variability such as the residual heterozygosity due to over-dominance, and the possibility of spontaneous mutation. The control of homozygosity is not easy. At the present time, such techniques as skin grafting are used that are of limited value, controlling only a small number of genes. The application of genetical tests, properly designed with adequate tester stocks, might help in this kind of control.

In all biological experiment variables must be applied one by one. This implies a rigid control of the external, and of what can be called the internal, environment, such as the flora of the animal. The composition of the pathogen burden of the animals is of the utmost importance. Conventional laboratory animals carry loads of microorganisms, which can be divided into several categories. These may be pathogens causing diseases, either in the form of epizootics with the possibility of carrier animals showing no signs of evident disease, or in the form of sporadic losses difficult to eradicate, but always impairing both production and experimentation. Pathogens may be present that do not cause evident disease, such as commensals influencing the reaction of experimental animals, or low-grade pathogens that can cause serious disease under experimental conditions.

Not less difficult is the assessment of nutritional status, for the criteria can be different: maximum growth, maximum reproduction, maximum life-span, maximum resistance or sensitivity. So the pattern of nutrition depends on the goal, in other words on the type of research for which the animal is going to be used.

The problems of environment were given a large place (35 per cent of the lectures), and included under this heading were all the papers dealing with techniques used in the production of pathogen-free and germ-free animals. The control of environment is indeed extremely important in the production and utilization of laboratory animals. The biologist is working with the phenotype of the animals, that is, organisms the characteristics of which are the result of heredity and environment. For some characteristics the influence of heredity is very low and the environment accounts for most of the phenotypic variability. Moreover, environment does not act only during the development of the animal; environmental conditions under which the animal is kept during the experiment have a definite influence on the results. Environment is taken in its broadest sense and includes the physical environment represented by the building, the air conditioning, heat, light, equipment, etc.; and it includes also many other factors, such as social factors that influence reproduction, for example, through olfactory stimuli.

Sessions on two days were devoted to the control of the mierobial environment, in other words, to the new techniques of germ-free life. Emphasis was put mainly on the technical aspects of the problem that apply not only to small laboratory animals but also to farm animals. The conception of buildings for mass production of 'clean' animals was presented, and attention directed to the numerous pitfalls in such an operation. Various techniques of sterilization were discussed, and the problem of the decontamination of personnel was investigated. In the husbandry of 'clean' animals, the biggest hazard is the animal technician, because of inefficient methods of decontamination.
A small part of the programme was devoted to the problem of strain specificity. Examples given by pharmacologists showed the differences among strains so far as sensitivity or resistance to specific drugs is concerned. In fact, a new discipline, pharmacogenetics, is developing, the main purpose of which is to study genetically determ. ined variations in animal species revealed by the effects of drugs.

One session covered the field of less usual laboratory animals, from cats and dogs to cockroaches.

The meeting directed attention to the following considerations. Problems related to the production of highquality laboratory animals are not relevant to husbandry alone. A scientific approach is now necessary to produce animals that must be considered as biological reagents. This new concept of the laboratory animal is a corollary of the fact that biological research has become more quantitatively minded in its approach to solving its problems; more and more exact sciences are penetrating into biology (biophysics, biochemistry), and this leads to the concept of the laboratory animal as a precise tool of research. The modern laboratory animal is a laboratory product, not a farm product. Up to the past two decades the biggest handicap was the indifference, both of many research workers and of others having responsibility in research programmes, to the importance of laboratory animals in the development of biological disciplines. The new attitude towards all these problems is now, fortunately, different, and more and more biologists regard now as elementary for their animals what were, some years ago, regarded as the highest standards.

The ideal laboratory animal, such as the user needs, would show some characteristics that can be defined in detail, but which are not always easily obtained. It should have a genetical background as precisely defined as genetical science allows; its food must be perfectly balanced and cover all its nutritional requirements at any time of its life; it must be free of all micro-organisms susceptible of interfering with the development of the experiment and, finally, it must present the specific characteristics that the experimenter is looking for. All these conditions have to be met in organisms that are growing, reproducing and dying, generation after generation, or, in other words, secured in individuals in constant evolution that consequently cannot be standardized in the real meaning of the term. Standardization implies that objects submitted to a control of conformity can be compared with those measured by a fixed and invariable standard. It is not possible to fix such standards with living material. Rather, it is necessary to resort to the expedient of descriptions or specifications, which may be considered as the equivalents of standards used in the physical sciences. It is possible to specify to a certain extent the genetical state of organisms, their health status, their nutritional status and their performances (sensitivity or resistance). Such a conformity control, however, needs for each specification an enormous amount of scientific and technical work. This work cannot be performed, for obvious reasons, on all animals directly used as experimental animals and must be applied on the basis of a sample, or in other words, on a small number of representative animals. In addition, all these operations have to be repeated regularly in order to detect any deviation in any one of the specific characteristies defined.

Out of these considerations of the control of quality a genoral pattern concerning the organization of the production of laboratory animals arises: (1) There is a general agreement on the need for specifications, which must be formulated in well-defined, terms with precise moanings and carrying universal acceptance. (2) There is a need for centres where specified laboratory animals are maintained under strict control, conforming with established definitions. Such centres, designated as "primary type colony centres", are animal stations maintaining "colonies of any laboratory animals defined genetically and of 
known nutritional and disease status". The function of such centres is to provide breeding stock for sub-cultivation elsewhere. To enlarge on these primary type colony centres, they can be organized on the basis of national centres that are usually controlled by official bodies. Such organizations exist at the present time in about a dozen countries, and will soon be found in more. The staff of these centres must include scientists as well as properly trained technicians, in order to apply all the required controls to the animal colonies under their care.

This kind of operation is necessarily costly: for this reason each primary type colony is usually limited to about 100 pairs of animals. Animals produced in these centres are not used directly for experimentation, but as breeding nuclei of high value, from which it is possible to create mass production units, where animals not essentially differing from the strictly controlled animals of the original primary type colony may be produced. This implies that these units should not breed away more than a few generations from the primary type colony, in other words that each production unit should regularly get new breeding stock from the primary type colony centre. This policy is the best safeguard against possible deviation and differentiation from the original defined stock. From the point of view of genetics, such a system prevents the splitting up of major strains into sub-strains that, after a few generations, will be more or less different from the mother strain. From the point of view of health status, primary type colonies are also a necessity. Because of the considerable expenditure in the way of competence and resources for the production of gnotobiotic animals, efforts must be concentrated on primary type colony centres, in order to provide laboratories with all the necessary means (isolators, competent staff, etc.) for keeping nuclei of gnotobiotes of different species and strains. Such nuclei will give any animal unit engaged in production the possibility of rebuilding regularly, if occasion demands, its different colonies from animals with defined flora. As at present conducted, recontamination with undesirable micro-organisms is not a rare event in large production units run under so-called specific pathogen-free conditions; through faulty technique or, frequently enough, through contact with animal technicians. Gradually a colony will build up a flora of its own, different from what it was in the original stock and different from that in other colonies.

Production units have to run on economic lines and can eventually make money if they provide animals to other laboratories, whereas primary type colony centres cannot be expected to be self-supporting. Their operation is a costly enterprise on account of the variety of strict controls that have to be applied to these animals, and of the refined techniques and the highly competent staff needed. In addition, in most cases, national primary type colony centres have to maintain an inconveniently large number of strains of different species, many of which are infrequently demanded. On account of these stringent requirements for conformity with specification, very few national centres, not to say none, in existence to-day correspond to the definition of an ideal primary type colony centre.

Out of this discussion arises the question of the necessity for a few regional centres, run on an international basis with powerful financial means. An international centre should be able to provide any national centro in the area covered by its activity with breeding nuclei of speci. fied animals of all strains of different species. It should carry on large research programmes, mainly in the fields of research relevant to the production of high-quality animals: geneties, nutrition, pathology, as well as hus. bandry in general that includes, as well as the care of the animal, both the influence and control of its environment. Finally, an international centre should provide suitable training, particularly for scientists aspiring to take chargo of animal divisions (national centres or production units), especially in geneties as applied to laboratory animals, and in the new techniques of germ-free life.

In line with other fields of research, this new field, called 'laboratory animal seience', cannot develop without international co-operation. Progress realized in the field of laboratory animals in different parts of the world can only be fragmentary, but it can be accelerated and generalized through intense international contacts, exchange of scientists through scholarships, exchange of consultants, publications, meetings. All these activities directed at international co-operation are, in fact, being pursued by the International Committee on Laboratory Animals. This organization has been able, since 1957, to work along these lines through the generous support of the most important organizations: the World Health Organization, the United Nations Educational, Scientific and Cultural Organization, and also the International Union of Biological Sciences, the Council for International Organization of Medical Sciences, the International Union of Physiological Seiences, the International Union Against Cancer and the International Union of Biochemistry.

To summarize the present trends concerning the provision of laboratory animals, it may be said that there is an increasing demand for defined laboratory animals. Quality controls are necessary for which competent scientists and fully trained technicians are indispensable. In addition, more elaborate facilities are necessary to create an optimum constant environment. Consequently the cost of laboratory animals of the future will definitely increase, and more provision will have to be made in the budgets of research laboratories under the heading of laboratory animals.

Standardized specifications for laboratory animals are conceivable only through some degree of centralization. For this reason, official centres breeding animal stocks in conformity with specification are necessary. International primary type colony centres could be created, and national centres are being developed. In some countries, large production stations will be equipped to produce experimental animals on an industrial basis.

Public health is the concern of the whole of humanity, and is entirely dependent on progress made in biological and medical research. Laboratory animals are the raw material on which these sciences are working. It is, therefore, of vital importance for the advancement of medical knowledge that large numbers of high-quality laboratory animals be produced. This is an international problem.

M. A. SaBoURdy

${ }^{1}$ Living Animal Material for Biological Research. Proc. Intern. Comm. Lab. Animals Symp., edit. by Lane-Petter, W. (International Committee on Laboratory Animals, Carshalton, 1958).

${ }^{2}$ The Problems of Laboratory Animal Disease. Proc. Second Intern. Comm. Lab. Animals Symp, edit. by Harris, R. J. C. (Academic Press, London, 1962).

s Patterson, J. S., Quality in Laboratory Animals, Laboratory Animals Centre Collected Papers, 8, 5 (1959).

\section{PUBLIC HEALTH AND OUTPATIENT NURSING}

TMPORTANT among the many publications of the World Health Organization are its Public Health Papers, which publish, for the general public, papers which have been prepared for the Organization on particular health questions. One of these questions-the shortage of well-trained nurses and the problem of how our hospitals should be staffed-is a serious matter in almost every country in the world. In Public Health 